\title{
HEPATITIS AGUDA GRAVE POR COINFECCIÓN POR VIRUS EPSTEIN-BARR Y CITOMEGALOVIRUS - REPORTE DE CASO Y REVISIÓN DE LA LITERATURA
}

\author{
SEVERE ACUTE HEPATITIS BY COINFECTION BY EPSTEIN-BARR VIRUSES AND \\ CITOMEGALOVIRUS - CASE REPORT AND REVIEW OF LITERATURE

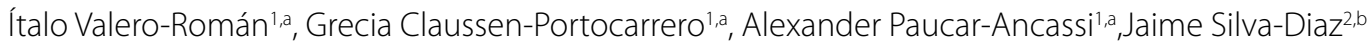

\begin{abstract}
RESUMEN
Se reporta el caso de una paciente de 6 años con antecedente de dermatitis atópica. Días antes de hospitalizarse presentó rinorrea y tos. Posteriormente presentó lesiones maculopapulares, alza térmica y coloración amarillenta de la piel. Luego de ser hospitalizada, además de los síntomas descritos, presentó 2 episodios de epistaxis espontánea, hematemesis y melena; mientras que en el examen físico se evidenció ictericia mucocutánea, fiebre, rash maculopapular generalizado, adenopatías, y hepatoesplenomegalia. En el estudio de imágenes se encontraron signos que indicaron indirectamente hepatitis aguda y derrame pleural. Por otro lado, entre los resultados serológicos se encontró que los marcadores de infección aguda por VEB y CMV, al igual que el marcador de infección crónica por VEB, fueron positivos.

Hasta donde tenemos conocimiento, este es el primer reporte en nuestro medio de coinfección CMV-VEB, debido a una infección aguda por CMV. Reportamos el caso y realizamos una revisión de la literatura.
\end{abstract}

Palabras clave: Hepatitis viral; Citomegalovirus; Ebstein-Barr (fuente: DeCS BIREME).

\begin{abstract}
We report the case of a 6-year-old patient with a history of atopic dermatitis. Some days before her hospitalization she presented rhinorrhea and cough. Subsequently she presented maculopapular lesions, increase of body temperature and yellowing of the skin. After being hospitalized, in addition to the symptoms described, she presented 2 episodes of spontaneous epistaxis, hematemesis and melena; while in the physical examination, mucocutaneous jaundice, fever, generalized maculopapular rash, lymphadenopathy, and hepatosplenomegaly were evident. In the images studies, signs that indirectly indicated acute hepatitis and pleural effusion, were found. On the other hand, among the serological results, it was found that the markers of acute infection by EBV and CMV, as well as the marker of chronic EBV infection, were positive.

As far as we know, this is the first report of CMV-EBV coinfection in our, due to an acute CMV infection. We report the case and we carry out a review of the literature.
\end{abstract}

Key words: Viral hepatitis; Cytomegalovirus; Epstein-Barr (source: MeSH NLM).

\footnotetext{
${ }^{1}$ Universidad Ricardo Palma, Facultad de Medicina, Lima-Perú.

${ }^{2}$ Hospital Guillermo Almenara Irigoyen, Lima-Perú.

a Alumnos de pregrado.

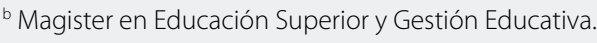

Citar como: Ítalo Valero-Román, Grecia Claussen-Portocarrero, Alexander Paucar-Ancassi, Jaime Silva-Diaz. Hepatitis aguda grave por coinfección por virus Epstein-barr y Citomegalovirus - reporte de caso y revisión de la literatura. Rev. Fac. Med. Hum. Enero 2020; 20(1):158-161. DOI 10.25176/RFMH. v20i1.2253 


\section{INTRODUCCIÓN}

Agentes virales como el citomegalovirus (CMV), EpsteinBarr (VEB), herpes simplex 1 y 2 , varicela-zoster, herpes humano 6, 7, y 8, parvovirus B19 y adenovirus pueden causar daño hepático agudo e inclusive presentarse como hepatitis fulminante(1). De estos, el VEB es el que mayor afectación hepática presenta de acuerdo a su intensidad y duración, además de ser la causa etiológica viral de citotoxicidad hepática de mayor frecuencia después del $\mathrm{CMV}^{(2)}$.

La afectación hepática, con o sin hepatoesplenomegalia, se presenta en el $30-60 \%$ de los pacientes con aumento del AST y ALT, fosfatasas alcalinas (patognomónico) e incluso ictericia por aumento de la bilirrubina ${ }^{(1-3)}$, teniendo una presentación de menor severidad en niños que en adultos mayores de 30 años 2 . La mayoría de casos de mononucleosis infecciosa cursan con una leve y autolimitada elevación del TGO y TGP(4).

La identificación del virus de Epstein Barr se realiza mediante marcadores como los anticuerpos heterófilos (test de Paul-Bunnell), la determinación del antígeno nuclear del genoma viral, la presencia de linfocitos atípicos en sangre periférica y anticuerpos de tipo $\lg \mathrm{M}^{(2,4)}$.

No existen criterios específicos para el diagnóstico de hepatitis por el VEB, pero existe un acuerdo general que los siguientes datos deben ser positivos para establecer su sospecha: elevación de aminotransferasas, infección activa del VEB definida por serología, cambios patológicos típicos según biopsia hepática y demostración del genoma viral en tejido hepático por medio de estudios moleculares ${ }^{(1)}$.

\section{REPORTE DE CASO}

Paciente de sexo femenino de 6 años natural de Huánuco, con el antecedente de dermatitis atópica diagnosticada a los 2 años, inició su padecimiento 6 días antes de ingresar al hospital con rinorrea y tos, fue automedicada por su madre con azitromicina $y$ paracetamol. 2 días después aparecieron lesiones maculopapulares eritematosas en cara, que se extendieron por todo el cuerpo. Posteriormente se agregó fiebre, ictericia (pigmentación de piel, escleras y coluria). 4 días después es hospitalizada, en donde persisten todos los síntomas, además de presentarse 2 episodios de epistaxis espontánea, hematemesis y melena. A la exploración física se encontró ictericia y palidez de mucosas, temperatura de $38,2^{\circ} \mathrm{C}$, rash maculopapular eritematoso en rostro, cuello, ambos miembros superiores, tórax, abdomen y pelvis, además de adenopatías $<0,5 \mathrm{~cm}$ en región cervical, axilar e inguinal, murmullo vesicular disminuido en ambos campos pulmonares, matidez abdominal, abdomen distendido, hígado palpable $7,5 \mathrm{~cm}$ debajo del reborde costal derecho y punta de bazo palpable. Los resultados de laboratorio al ingreso y evolución son los siguientes:

Por otro lado, la ecografía al ingreso reportó hepatoesplenomegalia y signos de colecistitis alitiásica de tipo reactiva, que fue interpretado como un signo indirecto de hepatopatía aguda. Durante su hospitalización se le realizó una TAC que confirmó presencia de signos sugerentes de un proceso linfoproliferativo, hepatoesplenomegalia, líquido libre intraperitoneal, como también signos tomográficos de cistitis, efusión pleural bilateral, el cual condicionó el desarrollo de atelectasias. Los resultados del panel viral fueron: anti HVA IgG, anti CMV IgM y anti VEB $\operatorname{lgM}$ e IgG positivos. El diagnóstico fue definido como hepatitis por coinfección VEB-CMV. El manejo se inició con transfusión de un paquete globular y plasma fresco congelado, además de la dieta blanda, ácido ursodesoxicólico, paracetamol condicional a la fiebre y control de peso diario durante la evolución. La evolución de la paciente fue favorable, el trastorno de coagulación secundaria a la hepatitis se resolvió, los exámenes auxiliares en la evolución evidenciaron que la bilirrubina total y directa disminuyeron diariamente, al igual que las transaminasas y el PCR.

Tabla 1. Resultados de exámenes auxiliares.

\begin{tabular}{|c|c|c|}
\hline Hemograma & Ingreso & Evolución \\
\hline Hemoglobina & $9,8 \mathrm{~g} / \mathrm{dl}$ & $12,3 \mathrm{~g} / \mathrm{dl}$ \\
\hline Leucocitos & $6600 / \mathrm{mm} 3$ & $3930 / \mathrm{mm} 3$ \\
\hline Plaquetas & 122000 & 204000 \\
\hline Coagulación & Ingreso & Evolución \\
\hline TP & 16,9 & 10,9 \\
\hline TTP & 37,6 & 37,7 \\
\hline Perfil hepático & Ingreso & Evolución \\
\hline Bilirrubina T & $10,6 \mathrm{mg} / \mathrm{dl}$ & $7,4 \mathrm{mg} / \mathrm{dl}$ \\
\hline $\mathrm{BD}$ & $5,3 \mathrm{mg} / \mathrm{dl}$ & $6 \mathrm{mg} / \mathrm{dl}$ \\
\hline $\mathrm{Bl}$ & $5,4 \mathrm{mg} / \mathrm{dl}$ & $1,4 \mathrm{mg} / \mathrm{dl}$ \\
\hline Fosfatasa alcalina & $1698,1 \mathrm{UI} / \mathrm{L}$ & $871 \mathrm{UI} / \mathrm{L}$ \\
\hline TGO & $279 \mathrm{UI} / \mathrm{L}$ & $181 \mathrm{UI} / \mathrm{L}$ \\
\hline \multirow[t]{2}{*}{ TGP } & $117 \mathrm{UI} / \mathrm{L}$ & 142 UI/L \\
\hline & Ingreso & Evolución \\
\hline PCR & 60 & 5,1 \\
\hline LDH & $2653 \mathrm{UI} / \mathrm{L}$ & \\
\hline
\end{tabular}




\section{DISCUSIÓN}

El citomegalovirus pertenece a la familia de los virus herpes de clase $\beta$. La infección primaria por este virus suele ser adquirida durante la infancia; posteriormente establece un periodo de persistencia a través de las células mieloides o granulocíticos. ${ }^{(5,6)}$ La reactivación o reinfección por virus exógenos es posible y causa alta mortalidad en pacientes inmunocomprometidos, como los que padecen algún tipo inmunodeficiencias o pacientes transplantados. ${ }^{(5,7)}$

EIVEB es un virus herpes de clase $\gamma$. La infección primaria suele manifestarse con un cuadro de mononucleosis infecciosa, caracterizado por fiebre, faringitis y linfadenopatía cervical con o sin hepatoesplenomegalia. EI VEB desarrolla persistencia en los linfocitos $B .^{(5)}$

Ambos virus son causa común del síndrome mononucleosido, y se estima que su prevalencia en adultos es mayor al $90 \% .{ }^{(8)}$ La reactivación de estos virus es posible, sobre todo en pacientes con alguna inmunodepresión. La infección primaria suele ocurrir poco después que el lactante pierde los anticuerpos maternos que poseía. Los infantes son una población de alto riesgo para infectarse con CMV y VEB, y estos virus pueden causar depresión del sistema inmune en niños, originando infecciones recurrentes de diversos tipos. ${ }^{(8,9)}$

Por lo mismo que el CMV y el EBV tiene tanto en común, la coinfección es común en pacientes pediátricos. ${ }^{(8)}$ Para explicar la coinfección por estos dos virus de la familia herpes hay varios mecanismos que se proponen. ${ }^{(10)}$ Podría ser una coinfección, o la reactivación del VEB que estuvo latente en los linfocitos como consecuencia de la infección del citomegalovirus. La coinfección si se ha descrito, pero de poca frecuencia y siendo casi restringido a la edad pediátrica. ${ }^{(8,10)}$ Estos virus pueden infectar a pacientes inmunocompetentes simultáneamente con otros agentes como son el virus sincitial respiratorio, Chlamydia pneumoniae, virus del sarampión, entre otros. ${ }^{(8)}$

La hepatitis por el VEB raras veces puede ocurrir sin un cuadro de mononucleosis infeccioso previo, lo cual dificulta más el diagnóstico etiológico.(11) Se postula como mecanismo que el virus infecta a los linfocitos $T$, en los cuales perpetúan causando una mayor actividad de células T. Lo que provoca inflamación del parénquima hepático con incremento de enzimas. ${ }^{(12)}$

La infección por CMV es generalmente asintomático; $y$, cuando no lo es, sus manifestaciones varían con la edad y con el estado del sistema inmune del paciente. Por ejemplo, recién nacidos infectados presentan retardo de crecimiento intrauterino, ictericia, hepatoesplenomegalia, microcefalia, daño cerebral, calcificaciones intracerebrales y coriorretinitis. Si la infección se adquiere en edades escolares y preescolares, suele manifestarse en forma de neumonía (bronquial o intersticial), rash cutáneo petequial, diarrea o hepatitis con discreta hepatomegalia. ${ }^{(13)}$

La paciente presentó elevación de TGOy TGP con valores tres veces por encima del valor normal, con predominio de TGO sobre TGP. Aparte hubo un incremento de bilirrubina directa y GGTP lo que implica un síndrome colestásico intrahepático, que se relaciona a infecciones virales. $^{(14,15)}$

Para el diagnóstico de infección primaria de VEB, se necesita de marcadores serológicos, entre estos la presencia de anticuerpos contra el antígeno del capside (VCA) es diagnóstico, pudiendo ser lgM o lgG, debido a que esta es producida tempranamente entre los días 4 a $7 .{ }^{(15,16)}$ Para el CMV se necesita tener IgM contra CMV para casos agudos, y la presencia de lgG expresa infección previa. ${ }^{(8,16)}$. La paciente presento positividad a IgM tanto para CMV y VEB, e IgG para VEB. Con lo que se estableció el diagnóstico de coinfección viral, en donde probablemente la infección por VEB se haya reagudizado debido a la infección aguda por CMV.

La evolución de la paciente fue favorable, no desarrolló insuficiencia hepática. El manejo fue solo con medidas de sostén (paracetamol) y con ácido ursodesoxicólico.

El exantema que presentó la paciente se relacionó con una reacción alergia al fármaco azitromicina. El tipo de exantema más asociado a antibióticos es el maculopapular. $^{(17)}$

Contribuciones de autoría: Los autores participaron en la concepción, recolección de información, redacción y aprobación de la versión final del artículo.

Financiamiento: Autofinanciado.

Conflicto de interés: Los autores declaran no tener conflictos de intereses en la publicación de este artículo.

Recibido: 20 de octubre del 2019

Aprobado: 07 de noviembre del 2019

Correspondencia: Ítalo Valero Román.

Dirección: Tortulas 135-Cedros de Villa Chorrillos, Lima-Perú.

Teléfono: +1949882647

Correo:ivr8195@gmail.com 


\section{REFERENCIAS BIBLIOGRÁFICAS}

1. Gallegos-Orozco JF, Rakela-Brödner J. Hepatitis viruses: Not always what it seems to be. Rev Med Chil. 2010;138(10):1302-11. Disponible en: https:// www.ncbi.nlm.nih.gov/pubmed/21279280

2. Pina DI, Cantón OS. Hepatopatía aguda. Protoc diagnóstico-terapéuticos Gastroenterol Hepatol y Nutr Pediátrica SEGHNP-AEP [Internet]. 2014 Disponible en: https://www.aeped.es/sites/default/files/documentos/hep aguda.pdf

3. Moreira E, Machado Â, Machado L, Xavier C, Monteiro C, Cunha J, et al. Infecção pelo vírus Epstein Barr e hepatite. Nascer e Crescer. 2011; 20(2): 73-5. Available from: http://www.scielo.mec.pt/pdf/nas/v20n2/v20n2a03.pdf

4. Barreales M, Pérez-Carreras M, Meizoso T, Garrido M, Masedo A, Colina F, et al. Infección por el virus de Epstein-Barr y hepatitis aguda colestásica. An Med Interna. 2006;23(10):483-6. Disponible en: http://scielo.isciii.es/scielo. php?script=sci_arttext\&pid=S0212-71992006001000006

5. Hu J, Zhao H, Lou D, Gao H, Yang M, Zhang X, et al. Human cytomegalovirus and Epstein-Barr virus infections, risk factors, and their influence on the liver function of patients with acute-on-chronic liver failure. BMC Infect Dis. 2018; 18(1): 577. Disponible en: https://www.ncbi.nlm.nih.gov/pubmed/30445927

6. Ljungman P, Hakki M, Boeckh M. Cytomegalovirus in hematopoietic stem cell transplant recipients. Infect Dis Clin North Am [Internet]. 2010 Jun 1 [cited 2019 Jun 13];24(2):319-37. Available from: http://www.ncbi.nlm.nih.gov/ pubmed/20466273

7. Vietzen H, Görzer I, Honsig C, Jaksch P, Puchhammer-Stöckl E. Association between antibody functions and human cytomegalovirus (HCMV) replication after lung transplantation in HCMV-seropositive patients. J Hear Lung Transplant [Internet]. 2018 Feb 18 [cited 2019 Jun 13]; 37(2): 299-302. Disponible en: http://www.ncbi.nlm.nih.gov/pubmed/28750933

8. Wang X, Yang K, Wei C, Huang Y, Zhao D. Coinfection with EBV/CMV and other respiratory agents in children with suspected infectious mononucleosis. Virol J. 2010;7:247. Disponible en: https://doi.org/10.1186/1743-422X-7-247

9. Owayed AF, Campbell DM, Wang EEL. Underlying Causes of Recurrent Pneumonia in Children. Arch Pediatr Adolesc Med [Internet]. 2000 Feb 1 [cited 2019 Jun 13];154(2):190. Disponible en: http://archpedi.jamanetwork.com/ article.aspx?doi=10.1001/archpedi.154.2.190
10. Peña Irún Á, González Santamaría A. Inmunoglobulina M positiva para citomegalovirus y virus de Epstein-Barr en un paciente con mononucleosis infecciosa. ¿Cómo lo interpretamos? Semergen [Internet]. 2012 Oct 1 [cited 2019 Jun 13];38(7):479. Disponible en: https://linkinghub.elsevier.com/ retrieve/pii/S1138359312001530

11. PAULA VIVIANI G. CSA. Falla hepática fulminante por virus Epstein Barr. Rol de los corticoides. Caso clínico. Rev. Chil. Pediatr. 2013; 84(3): 313 - 17. Disponible en: https://scielo.conicyt.cl/scielo.php?script=sci_ arttext\&pid=S0370-41062013000300010

12. Hernández-Estrada S, Aguilar Domínguez C, Lizardi Cervera J. Hepatitis por virus Epstein-Barr: Reporte de un caso. Médica Sur. 2005; 12(3): 1779. Disponible en: https://www.medigraphic.com/pdfs/medsur/ms-2005/ ms053e.pdf

13. Tori C, Leon Barua R, Roe C. Hepatitis por citomegalovirus: Presentación de dos casos. Rev Med Hered. 1995; 6(2):102-4 Disponible en: http://www.scielo. org.pe/scielo.php?pid=S1018-130X1995000200008\&script=sci_arttext

14. Del Valle Díaz S, Piñera Martínez M, Medina Gonzales N, Sanchez Vega J. Colestasis un enfoque actualizado. MEDISA. 2017;21(7):876. Disponible en: http://scielo.sld.cu/pdf/san/v21n7/san14217.pdf

15. Khoo A. Acute cholestatic hepatitis induced by Epstein-Barr virus infection in an adult: A case report. J Med Case Rep. 2016 Mar 27;10(1). Disponible en: https://www.ncbi.nlm.nih.gov/pubmed/27037083

16. Cameron B, Flamand L, Juwana H, Middeldorp J, Naing Z, Rawlinson W, et al. Serological and virological investigation of the role of the herpesviruses EBV, CMV and HHV-6 in post-infective fatigue syndrome. J Med Virol. 2010 Oct;82(10):1684-8. Disponible en: https://www.ncbi.nlm.nih.gov/ pubmed/20827765

17. Cordero Castro C, Martínez Moreno C, Rojo Conejo P. Guía ABE Infecciones en Pediatria. Guía rápida para la selección del tratamiento antimicrobiano empírico. 2010. Disponible en: https://guia-abe.es/anexos-reaccionescutaneas-por-antibioticos

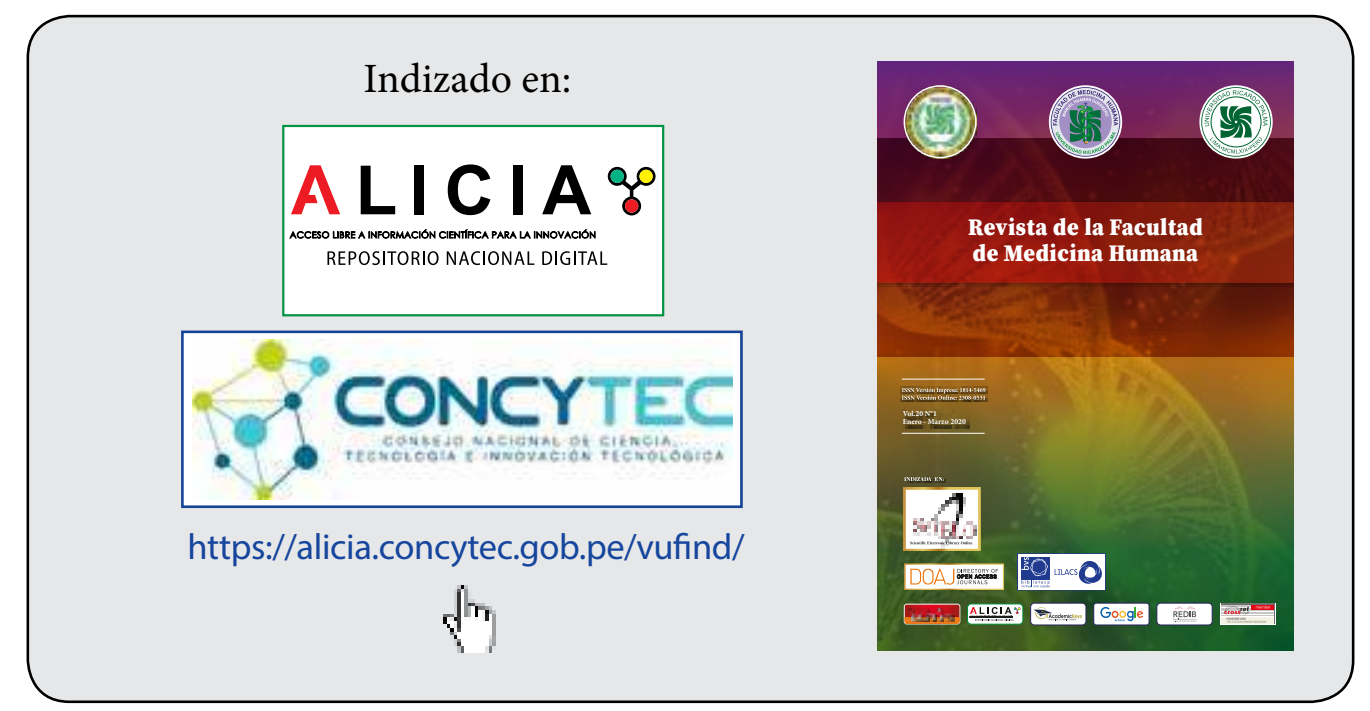

